\title{
The Effect of Technology in Realization between Implicit Meaning and Language Using in Higher Education to Effectiveness Communication
}

\author{
${ }^{1}$ Fatma, ${ }^{2}$ Sumarlam, ${ }^{3}$ Sarwiji Suwandi, ${ }^{4}$ Ani Rakhmawati \\ ${ }^{1}$ fatmakasim@student.uns.ac.id, ${ }^{2}$ sumarlam@staff.uns.ac.id, ${ }^{3}$ sarwijiswan@staff.uns.ac.id \\ 4anirakhmawati@staff.uns.ac.id
}

Universitas ebelas Maret University, Indonesia

\begin{abstract}
Astract: A meaning has a closed relationship to three things that is the cultural social system or reality, the users of the language, and social context. It shows that a sentence contains some meaning which is only owned by the users of the language. This study is focused on the effectiveness of communication in Language, which is colored by the use of Central of Sulawesi local language. By using descriptive qualitative research method and interactive model analysis, it is founded a research finding of response through pragmatic sentences in directive speech act variety. The intended speech act is sourced from: (1) all response forms which it is directed, either in answering question, responding to a command, instruction, invitation, or suggestion, and also responding to an explanation, affirmation, praise, or correction, and (2) spontaneous utterance which is directed to the speech partner in speech act with illocution power of asking, repeating, asking for explanation, questioning, something which is not known, asking for confirmation, or asking for turn. In understanding comprehensively, the class discourse, all events happened in the class are related to the cooperation principles, relationship pattern, meaning event which is adjusted to the situational context and cultural context of the communication act participants which have potential to maintain the principles or even violate one of the principles in accordance to each purpose in the speech act.
\end{abstract}

Keywords: Effectiveness communication, academic discourse, directive speech act, classroom interaction, local language

\section{Introduction}

The use of language as a socio-cultural reflection is important in the society. Language is used appropriately if it is suitable to the context[1]. Consequently, there are two situations in using language, formal and informal situations. In formal situation, standardized language is used since in this situation, language is not only a means to communicate instead to express an idea. Meanwhile, in informal situation, the use of language is related to how language is used in daily life[2]. Therefore, in informal context, the use of local language is acceptable. Naturally, in spoken language, people tend to use Bahasa which is influenced by the speaker's local dialect and accent.

The effectiveness of communication can be seen on two aspects, the response given by the interlocutor based on the locutor's locution and the communication strategies used that are affected by the multicultural aspects as well as the uniqueness of certain ethnicities [3]. The same thing happens on the context in which Indonesian Language is used which is affected by the speakers' local language as their second language. The effectiveness of communication using Bahasa that is affected by the local languages is expounded afterwards based on the interlocutor's response and the communication strategies used. And, now, Media influence insociolinguistics too. Experiencing speech without being able to interact with the 
speaker (or speakers), as when listening to the radio or watching television or film, only became possible at the turn of the twentieth century, and in the form of mass communication, a few decades later. It is almost redundant to point out that the majority of documented - and reconstructed - language changes have taken place without the broadcast, or even printed, mass media being[2].

In the communication management perspective, the effectiveness of communication is determined on the success of message delivery from the locutor by considering the aspects of audience that can be either subjective or collective. In order to achieve the effectiveness of communication, shared knowledge towards the topic and the intention that want to be met is needed, so that misunderstanding can be avoided. There are several interrelated aspects affecting the effectiveness of communication: demographic, psychographic, information transfer process, and linguistic proficiency[4]. Media influence in sociolinguistics Experiencing speech without being able to interact with the speaker (or speakers), as when listening to the radio or watching television or film, only became possible at the turn of the twentieth century, and in the form of mass communication, a few decades later. It is almost redundant to point out that the majority of documented - and reconstructed - language changes have taken place without the broadcast, or even printed, mass media being.

The lecturer and undergraduates' social interaction patterns are systematical and continuous depicting their roles and functions inside the classroom. The interaction pattern stated by Sinclair and Coulthard[5] and Ellis[6] relates to the stimulus response pattern and feedback which known as IRF (Initiate-Respond-Feedback) that shows the role of the teacher in the class. Similarly, it is also found in the lecturing context. The progress of teaching and learning depends much on the way the teacher (in this case is lecturer) plays their roles that is supported by the activeness of the undergraduates.

\section{Literature Review}

\section{a. Technology Effect in Style Acquisition and Dialect-Idiolect as a tools effectiveness} communication

The role of mass media is very important remembering that mass media has important roles in various aspects. Related to language, one of them is vocabulary spread, either from foreign language or local language, of course by involving various kinds of mass media either printed or electronic. The spreading of vocabulary involves the actor of mass media. Information which is presented by mediaexample vocabulary, directly or indirectly has provided some data for everyone who composes dictionary to be used as a material in composing a dictionary, and later in order to be able to be used well and appropriately it needs to be reprocessed[2]. New vocabularies which come from foreign language or local language in Indonesian are not limited only on general vocabulary, but also vocabulary of technical terms. In this case, this vocabulary is used to fulfill the needs of language society on a certain science. Another role of mass media is building an influence through a determination of contexts and events construction by using language. Language which is used by massamedia is representing a certain social and political group. Some events which are considered appropriate to be published will tend to be used in society as a way to discuss a certain group or event.

\section{b. Teaching and Learning Process in Classroom Interaction}

Nowadays, ideal teaching and learning process is the one that gives bigger role for the students, so that the teacher's roles lessen[7]. However, in practice, the domination of the 
lecturer is still high; hence, the role of the students, in the class, is majorly as a interlocutor who give response to the lecturer as the locutor. One way to give response is by using local language in certain ocassion as an effort to improve the effectiveness of the communication.

In roling as a controller, in order to encourage the students to activeness, teacher can use several strategies; one of the strategies is by establishing closer and more comfortable interpersonal relationship. This condition arises various communication strategies uses including the use of local language to show politeness. In language teaching and learning context, politeness can shape the liveliness and comfort of the class[8]. The use of politeness strategies can shorten the distance between the teacher and the students which eventually the class can be more exciting than before.

Peng, Xie, \& Cai[9], further states that the use of apt politeness strategies encourages the students to study, make them understand what to do and how to do, as well as develop the students' attitude in accordance to politeness principles in communication. For example, the use of positive politeness strategies implies on the improvement of the students' confidence and establish comfortable and conducive learning activities. Calling the undergraduates with their nicknames besides making them feel concerned, they also feel that their distance towards the lecturer shortens. Moreover, by using local honorific vocatives. Such condition encourages the undergraduates' confidence and makes them feel comfortable in joining the teaching and learning process.

Jiang[10] in his research related to politeness, expounds that politeness is able to improve the effectiveness of interaction between speech acts participants. It is found by Nasser\& Alhija[11] in their research that the success of language strategy generates effective communication so that it enables the teaching learning process to run well. That way, the expected learning outcome will be greatly achieved. The same thing happens on the effectiveness of communication in the class marked by the local language choice in directive speech acts generated between the lecturer and the undergraduates and among the undergraduates themselves.

On the other ocassion, participants with different culture have distinctive formulation in local language choice. Some express their intentions explicitly and directly and some express it implicitly and indirectly. This difference probably happens due to the different cultural and situational context inside the class in which the communication process is emphasized which considers the level of efficiency, effectiveness, communication purpose accomplishment, accuracy, clarity of the message, and significance in interaction.

\section{c. Responses Participant as a Realization the Effectiveness Implicit Meaning}

On the level of communication purpose accomplishment, the use of direct speech acts strategies gives positive effects towards the effectiveness and accuracy of communication[12], such is affected previously by the distance between the lecturer and the students, the lecturer's power, and the use of face unthreatening language. Positive politeness is done by giving more attention or appreciation towards the classroom situation and condition by using social marker, approving, avoiding disagreement, showing intimacy, joking, conveying indirect intention, involving the students, having reciprocal relationship, and giving appreciation to the students.

On the same study, the use of directive speech acts is also affected by cultural context. This context also affects the politeness forms, functions, and strategies in realizing local language choices in the form of directive speech acts[13]. In social interaction, in order to preserve the politeness, people tend to maintain the harmony and continuity of the interaction and avoid face threatening acts in accordance to the norms. In teaching and learning context, lecturer and students use speech acts not only for explaining, asking, 
suggesting, motivating, asking for information; but also for managing interpersonal relationship by still saving the other faces.

The aforementioned notion is based on the assumption that there is a tendency between the lecturer and the students to save faces one to the others and to meet a successful communication. Besides, politeness strategies of the lecturer and the students are affected by: (a) social distance (D) between the lecturer and the students; (b) power (P) between the lecturer and the students, and (c) relationship level (R) between the lecturer and the students. Harmer [10] states that teacher has bigger power than the students. Factually, this really happens in the teaching and learning process. On certain ocassion, before a discussion, the lecturer has significant role to motivate the undergraduates to e more active. Different with the role of lecturer as participant or monitor; in doing this role, the lecturer has to lessen the power and try to establish close relationship with the undergraduates.

Bishop[14] identifies the two forms of teacher's power (P), sapiental and formal power. Sapiental power rises from the fact that teacher has deeper background and richer experience, while formal power is a power rises from the cultural background. The sapiental power lessens if the teacher regards the students having the same understanding and knowledge. Rowland analysis[15] towatds conversation between lecturer and undergraduates shows equal proportion in using politeness strategies. In the teaching and learning process, the undergraduates are regarded having the same level of understanding and knowledge from the lecturer. In other words, the lower the domination of the lecturer, the closer their distance is; which eventually implies the difference on directive speech acts forms, functions, and strategies used.

\section{Material \& Methodology \\ 2.1 Data}

Qualitative approach using a data collecting from the subjects are majorly about the subjects' communication process. This research is conducted in Tadulako University and Alkhairaat University in Central of Sulawesi its university with multi-ethnical context include male and female undergraduates as the subjects of study from many district area.

The data are in the form of spoken speech in academic discourse by lecture and students in the calssroom that using a direct speech act. The data analysis uses Miles and Huberman's[11] interactive model which involves (1) data collection, (2) data reduction, (3) data display, and (4) data verification or conclusion.

\subsection{Method}

This research is qualitative with the approach of SPEAKING ethnography of communication by Hymes. Pragmatic, gender, and ethnographic views are used in this research to understand specific local conditions based on cooperative and politeness principles in which the female undergraduates use refusal acts. In this research, not all the eight factors are used to explain the problem. Communicative design, in the perspective of this research, is based on the use of language which contextually has meaning; and it is used to know the social communicative function[16].

The speech context pragmatically eases the language analysis process. This research emphasizes on the use of speech context which involves extralinguistic and linguistic context. The former refers to socio-cultural aspect while the latter emphasizes on how language is used. Praag, Stevens, and Houtte[17] on their research, state that in order to realize the communication purpose, the speaker is encouraged to use strategy and interpretation in 
communication with the tool by the social norms that can explain the cultural background like a gender, social status, and knowledge setting between participant.

\section{Results and Discussion}

Similar to direct strategy, findings segmented into indirect strategy in local language directive speech acts involves strategies which function as a request, suggestion, imperative, refusal, and prohibition in Kaili, Malayan Bugis, and Malayan Manado languages.

\subsection{Indirect Strategy Functioning As A Request in Malayan Manado Language}

\section{Data [1]}

(1) Pt : Apa depe beda katu' itu puisi kontemporer dulu deng sekarang, Mala? 'What's the difference between old and contemporary poems?'

(2) Mt1 : Ada di halaman berapa itu depe penjelasan. Buka saja itu bukunya W.S Rendra yang torang so kopi kemarin, dang.

: 'It's on W.S Rendra's book that has been copied, maybe in a certain page. Just open the book.'

(3) Mt2 : Yang penting nganapahami dulu itu kontemporer koa' apa.

K : 'The important thing is that you have to understand first what contemporary is.'

$\mathrm{K} \quad$ : It is uttered by the undergraduate to the peer as a refusal to give further explanation about the thing being asked

Code $\quad$ : STL/TTD.f.pmt/08.03.17/03

At glance, the brief data above [1.2] is a common interrogative sentence uttered to indirectly ask the interlocutor to give an explanation. Without using any negation marker, based on the context of the conversation, the locutor expects explanation and comments on the thing the locutor asks. That utterance semantically and pragmatically a request in the form of direct interrogative sentence functioning to ask for something directly.

Generally, each utterance can represent one's culture. An utterance symbolizes its locutor's identity. In line, Ogunsiji, Farinde, and Adebiy[18] explains that a language (including speech acts itself) has something to do with maintainning interaction, power, and interpersonal norms acquired between male and female are extremely different. Male utters powerful speech acts while women's speech acts are powerless.

\subsection{Indirect Strategy Functioning As Suggestion in Malayan Bugis Directive Speech Acts}

\section{Data [2]}

(1) Pt : Begini, saya mau bertanya.

: 'This way, I want to ask.'

(2) Mt : Eh... belum pi pale. Wasettoni pura $\mathrm{Bu}$

(3) Pt : Torang masih bacurita.

: 'We are still sharing.'

(4) Mt : Belum selesai Oo, saya kira sudami bertanya kita Bu. Belum pale'(tertawa). 


\section{Sanggadi pi Bu, ada pi lagi materi nanti lebbireng ditahan.}

: 'Oh it is not over, right Mam? If we have questions, it is better for us to ask it the next meeting if we still discuss the same material.'

$\mathrm{K} \quad$ : It is uttered by the graduate to the peers so that they should ask anymore since the discussion is going to be ended

Code $\quad$ : STL/F.srn/09.01.17/02

Language use in a certain society covers politeness principles in its every utterance. In this matter, an utterance is considered polite if it is not directively uttered. Meanwhile, it is uttered indirectly or implicitly. This can be seen in the data [2.4]. It is a directive speech acts in Bugis language functioning as suggestion uttered by using indirective strategy. The utterance that means a suggestion is uttered in the form of interrogative [4.4] which is wasettoni pura. It means I think it is done. The meaning of that utterance is equal with 'oh it is not over yet, I think it is done.

The meaning of an utterance based on the context is a suggestion it is better that we stop now strengthens by the utterance [4.4] lebbireng ditahan. Since there are still some graduates who have not involved in the discussion, the locutor suggests that they ask in the next discussion. This shows that the locutor and the interlocutor need to understand both the form and the implicit intention (implicature) in communicating so that they can communicate well. Lakoff[19] expounds that politeness is an interpersonal relationship system aimed to ease interaction and lessen the conflict and confrontation that probably occur. Implicature makes speech acts more polite; an utterance intended to command may be uttered in the form of affirmative and so on.

\subsection{Indirect Strategy Functioning as Command in Malayan Manado Language}

An utterance that implies imperative meaning can be said as a kind of utterance that functions as imperative as it is. Briefly, Kunjana [14] classifies imperative sentence as five categories as (1) instruction, (4) request, (3) permission, (4) invitation, and (5) command.

In relation with the disagreement to refuse an instruction, the interlocutor (Mt) sometimes used a strategy to instruct the locutor $(\mathrm{Pt})$ back. This can be seen in the below conversation.

\section{Data [3]}

Pt : Tinggal sadiki ini kupon torang mo bikin apa

(4) Mt : Kase akang yang laeng jo. Jang kita.

'Give the coupons to others. Do not give it to me (again).'

(3) $\mathrm{Pt}$ : Baku ganti lah kan torang te apa!

: 'Let us sell the coupon alternately. It is ok.'

(4) Mt : Lihat tugas masing-masing jo. Nyanda salah ngana bilang pa kita itu!

'Do what we are assigned to! Are you sure that you say the right thing to me?'

$\mathrm{K}:$ : The undergraduate indirectly ask the peer to participate in selling their class bazaar coupon by offering it.

Code $\quad: \quad$ STL/F.pth/13.03.17/01

In the above dialogue, the interlocutor's utterance is an imperative in the form of declarative sentence. The thing that marks this intention is the existence of imperative marker 
in Manado language shown in the data [3.1] that does not only inform but also convey the real intention of that declarative sentence. This is supported by the context of the refusal consisting of place, topic, and participants. In their findings, $\mathrm{Su}$ [7] and Pallawa[20] reveal language choices used in speech acts are various.

Based on the context, the use of local language in the utterance makes the pragmatic intention easier to be understood by interlocutor (Mt). The use of local language, without influencing the good structure of the utterance, should be maintained in non-formal communication so that it is well preserved. Another pragmatic tool that is no less important in pragmatic studies in oral discourse is the cooperative principle that must be fulfilled in an act of communication or conversation. Hiver \& Whitehead[21] argued that the form of language use can be seen from several aspects, namely, content, type, reason for choosing topics, organization of topics, and data sequences and rules in the conversation that apply.

Briefly, in that utterance, there seems no connection between the locutor's $(\mathrm{Pt})$ and the interlocutor's (Mt) utterance. However, based on the context that Pt instructs Mt to sell the remaining coupons can be seen in utterance (1). Then, it isresponded by Mtby instructing $\mathrm{Pt}$ back by using indirective strategy. In that conversation, $\mathrm{Mt}$ is a male undergraduate while $\mathrm{Mt}$ is a female undergraduate. The refusal in above conversation can be found in utterance (4) and utterance (4). The form, strategy, and the context of refusal is indicated by negation marker nyanda', nda, andtetidak which are used independently in every undergraduate's refusal. The use of negation to show refusal is more meaningful if it is combined by other terms so that the form of refusal are different and specific.

Relationship among teacher's roles, interaction pattern, politeness forms, and politeness strategies can be drawn on a diagram as follows.

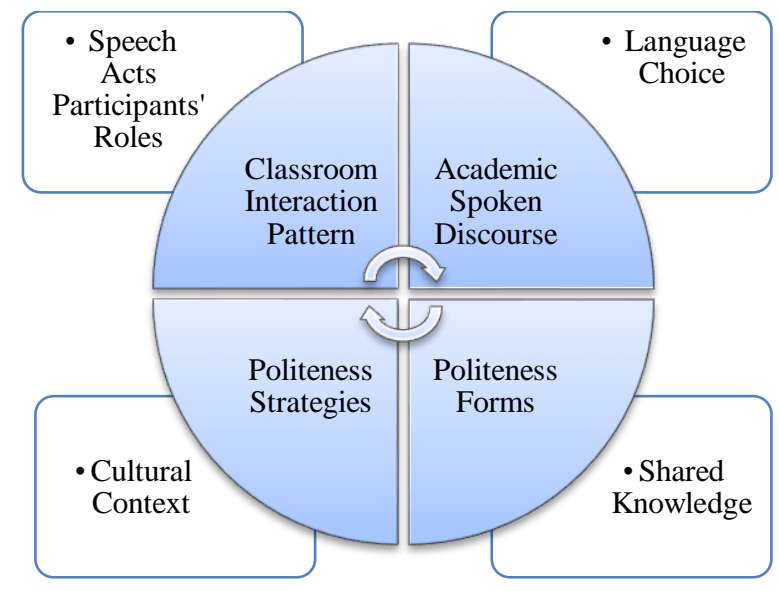

Fig. 4.1 The Relationship among Factors of Communication Effectiveness in the Class

\subsection{Indirect Strategy Functioning as Refusal in Malayan Bugis Language}

Refusal speech can be conveyed through directive or indirective speech. Directive speech is a kind of speech in which the function of the utterance is in line[11] For example, 
declarative sentence is used to utter statement, imperative sentence is used to utter command, and interrogative sentence is used to utter question. It is clearly different with indirect strategy, a kind of speech strategy that functions an utterance differently from its form. Interrogative sentence may be used to give command, declarative sentence functions as refusal, and so on. Below is the elaboration of indirect strategy used by female undergraduate to show her refusal to Mt. One of the examples is as follows.

\section{Data [4]}

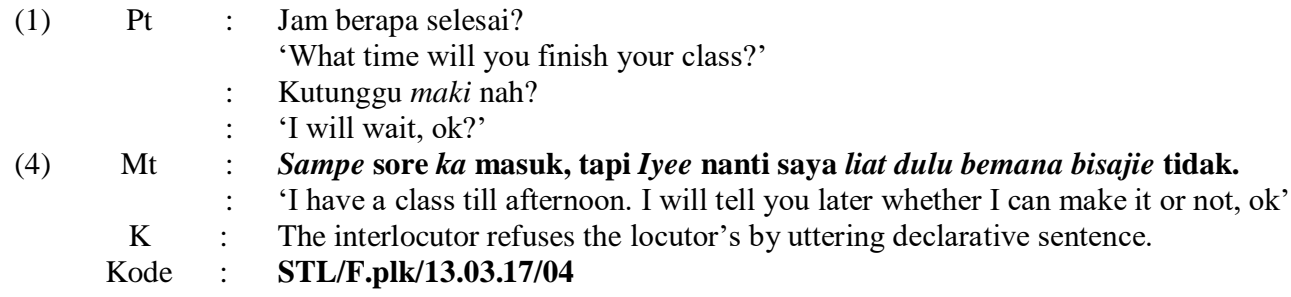

In the context of the conversation above, there is refusal found in data [4.4]. Although it involves refusal, the utterance contains the use of Bugis horrific to show politeness or respect to the interlocutor. Based on the social and cultural factor, it can be concluded that the social status and the same community which someone owns may become one of several factors to utter refusal by using indirect strategy[22].

This is stressed by Imai, Kanero, and Masuda [on their finding that in relation to the use of language, the culture in which we live influences our language use. The culture and the language affect one's language choice. Based on the social status underlying the utterance, the intimacy between $\mathrm{Pt}$ and $\mathrm{Mt}$ can be seen through marker iye' that means yes uttered to someone older to get more acquainted even though there is refusal speech. This is used by the female undergraduate to maintain the locutor's feeling by considering possessed norms and culture.

When the conversation takes place, the female undergraduate faces non-formal situation so that the word tidak (it means no and it is usually used in formal context) is not generally found. There is a tendency to use the word $n d a$ ' instead of tidak; this shows how negation nyada' and $n d a^{\prime}$ is used in refusal. In addition, there is horrific ki that means kita in Bahasa and we in English as the substitute of first person persona to respect Mt. It is shown in the context that the refusal is uttered regarding to the locutor's and interlocutor's same community. Moreover, the topic and the participants involved influence a kind of refusal selected by the female undergraduate.

\subsection{Indirect Strategy Functioning as A Prohibition in Malayan Manado Language}

This is one of directive speech acts forms in Malayan Manado language that implies prohibition used by undergraduates to their peers. The prohibition is uttered by using indirect strategy. This is the brief data on it.

\section{Data [5]}

(1) Pt1 : Odo, gaga nga pe suara e mar lebe bagus leh badiam. Te bisa torang konsen ko bikin.

: 'Wow, your voice is good, but it is better that you keep silent. We cannot 


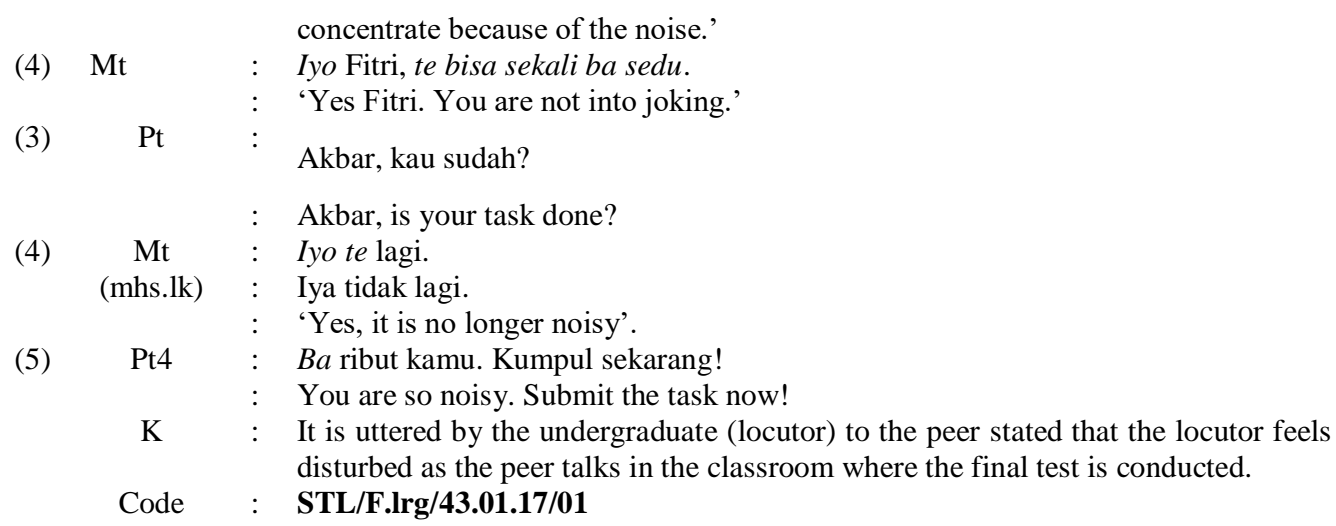

The prohibition is reflected in data [5.1] in the utterance odo, gaga nga pe suara $\boldsymbol{e}$ mar lebe bae ba diam; it is a statement that the interlocutor's voice is good. However, based on the underlying context involving indirect strategy, the declarative form of the utterance functions as prohibition used to forbid the interlocutor to make sound by uttering mar lebe bagus leh badiam. The locutor emphasizes the prohibition by using Malayan Manado language shown in data [5.1]te bisa torang ba konsen ko bikin that means the interlocutor's voice is able to disrupt peers' concentration in doing the final test.

The locutor chooses indirect to communicate the intention to the interlocutor by implying the prohibition occurs because the locutor is a female while the interlocutor is a male. Command, refusal, or prohibition of women's directive speech acts are expressed by using sarcasm and more obvious words choice. The use of sarcasm in prohibition is not intended to satirize but to show attention to the interlocutor so that the situation becomes conducive, communicative meaning is conveyed, and other activities are not interrupted[23].

It can be understood that language is composed of elements of forms (formal) and meaning. Naturally, language is used as a means to convey thoughts so that others can understand. Supatno[3] stated that the meaning is not independent of a perception. The knowledge of a language speaker has an important role in generating meaning. How to understand the speech act tenor's meaning and intention are related to text and context. The framework of thinking is analysing a text to understand what is being said, and to pay attention to when, where, who is involved, and the information behind the speech. Mey[24] argued that context is a dynamic concept and not a static concept. Therefore, context is understood as an ever-changing situation, which helps participants in the communication process to interact. With context, the expression of language used in interactions becomes understandable.

Liantada[25] explained the context as the background knowledge of what is considered to be shared by speakers and which helps them interpret their intentions in certain speeches. The use of language in social interaction does not only require syntactic and semantic rules of knowledge but also pragmatic knowledge. This requires knowledge of what is done by the tenors and why they do it, Steadmen, Kayi-Aiydar \& Vogel[7] Therefore, in understanding the intent of each utterance, understanding is needed including the overall habits of communicating including how to express their speech politely. Pragmatic understanding is considered to be very important because in the realm of oral academic 
discourse, in addition to building communicative competencies of students, it is also expected to be able to develop good speech.

\section{Conclusion}

The effectiveness of communication can be seen on two aspects, the response given by the interlocutor based on the locutor's locution and the communication strategies used that are affected by the multicultural aspects as well as the uniqueness of certain ethnicities Seman, Ahmad, Aziz, \& Ayudin[3] The same thing happens on the context in which Bahasa is used which is affected by the speakers' local language as their second language. The effectiveness of communication using Bahasa that is affected by the local languages is expounded afterwards based on the interlocutor's response and the communication strategies used.

The use of language is a form of the use of cultural social which has such a position in the society. The form of language using as a representation of cultural social is also reflected in the interaction pattern in the class between the lecturer and students as a consecutive and in order social contacts based on each role and function. The continuity of learning process inside the class depends on how participants play their role in maintaining the effectiveness of communication. The effectiveness of a communication can be seen from two aspects: response and the use of strategy choice in communication which can be affected by the multicultural aspects of character or the unique things of a certain ethnic. To comprehend comprehensively the class discourse, all the events that occur in classroom discourse are related to the principles by cooperation, relationship, meaning events that are adapted to the context of the situation and the cultural context of the act of communication that is possible to defend the principles of these principles according to their want meaning.

Furthermore, based on the description of the role and function of a teacher, the form of speech acts conducted by a lecturer towards their students in each role can be identified as follows: (1) as a controller, speech acts that appear can be in the form of directive, representative, or expressive speech acts. (4) as a class manager, the form of speech acts can directive in the form of illocutionary acts of giving orders, requesting, asking, giving instructions, and strengthening; (3) as a resource, the speech acts that arise are representative and directive; (4) as a tutor, teacher speech acts are realized in directive and representative speech acts, (5) as a motivator, teacher speech acts are realized in the form of directive, representative and expressive speech acts in inviting, asking, reminding, showing, affirming, praising, and congratulating.

This is considered to be able to develop a good speaking attitude. Inserting the awareness of personal and social skills can give a positive impact to the ability of the tenor in interacting well with the community, including in building the effectiveness of communication in the classroom. Indirectly, the use of local languages can help lecturers and students use social language rules such as how to greet well, show respect and gratitude, apologize, ask permission, and ask for help appropriately.

From the undergraduates' responses do emerge several speech acts. The responses involve: (1) every single response of the undergraduates both in answering the lecturer's questions and their friends'; responses of command, instruction, offering, suggestion, explanation, exclamation, compliment, as well as feedback; (4) the undergraduates' direct speech towards their friends in speech acts of requesting, repeating, asking for explanation, asking for something they donot know, asking for confirmation, and asking for taking turn. 
The interaction pattern inside the class shown from the roles of the locutor either as a lecturer or undergraduate implies the relationship pattern established from the communication process.

The interaction pattern between students and lecturer is one singular factor determining the use of politeness or politeness strategies used during their interaction. The factor that affects the politeness form between the locutor and interlocutor is social distances (D) and the imposition of risk (R). The improvement of the locutor's power (P) and social distance (D) can increase weight of FTA (Face Treathening Acts). This increasing affects the use of politeness in a higher state. The roles of teacher as a controller, manager, resource, tutor, motivator, and evaluator.

\section{Acknowledgement}

This research is fully supported by Ministry of Research, Technology and Higher Education, Directorate General of Higher Education, Ministry of Education and Culture, Republik of Indonesia (DRPM DIKTI), In accordance with Decree Number. 0045/E3/LL/ 2018 \& Research Contracts for Fiscal Year 2018 Number. 1136/K9/KT.03/2018.

\section{Reference}

[1] M. . Andrade, "The Successful Educational Journeys of American Indian Women: Forming Asppirations for Higher Education," Int. J. Multicult. Educ., vol. 16, no. 1, pp. 21-38, 2018.

[2] T. C. Stuart-Smith J., Language and the Influence of the Media: A Scottish Perspective. In: Lawson R. (eds) Sociolinguistics in Scotland. London: Palgrave Macmillan, 2014.

[3] A. . Seman, A.A., Ahmad, A.R., Aziz, Z., Ayudin, "The Effectiveness of Teaching and Learning History Based On Multicultural Towards National Integration in Malaysia," in Procedia Science, 2011, pp. 1588-1596.

[4] C. . Therkelsen, D.J., Fiebich, "Message to Desired Action: A Communication Effectiveness Model," J. Commun. Manag., vol. 5, no. 4, pp. 374-390, 2001.

[5] C. R. . Sinclair, McH, Towards an Analysis of Discourse. London: Oxford University Press, 1975.

[6] R. Ellis, Understanding Second Language Acquisition. Oxford: Oxford University Press, 1985.

[7] S. . Steadmen, A., Kayi-Aiydar, H., Vogel, From College Composition to ESL: Negotiating Professional Identities, New Understanding, and Conflicting Pedagogies. 2018.

[8] B. . Agustina, S, Cahyono, "Politeness and Power Relation in EFL Classroom Interaction: A Study on Indonesian Learners and Lecturer," Int. J. Lang. Linguist., vol. 3, no. 3, 2016.

[9] A. Nasser, F., Alhija, "Teaching in Higher Education: Good Teaching Through Students' lens," in Studies in Educational Evaluation, 2017, pp. 4-12.

[10] X. Jiang, "A Case Study of Teacher's Politeness in EFL Class," J. Lang. Teach. Res., vol. 2, no. 5, pp. 651-655, 2010.

[11] A. M. Miles, B. M. Huberman, Analisis Data Kualitatif. Jakarta: UI Press, 2014.

[12] K. . Harman, R., Dobai, "Critical Performative Pedagogy: Emergent Bilingual Learners Challenge Local Immigration Issues," Int. J. Multicult. Educ., vol. 14, no. 2, 
pp. 1-17, 2012.

[13] E. Tapio, "Focal Social Action Throuhg Which Space is Configured and Reconfigured when Orienting to a Finnish Sign Language Class," Linguist. Educ. 44, vol. 44, pp. 60-79, 2018.

[14] J. Bishop, A, Mathematical Encukturation. Academic Publisher, 1988.

[15] T. Rowland, The Pragmatics of Mathematics Education: Vagueness and Mathematical Discourse. London: Falmer Press, 1999.

[16] Mudiono, "Kajian Etnografi Tindak Ilokusi Asertif Bahaasa Indonesia dalam Pendidikan Informal," J. Pendidik. dan Pembelajaran (Educational Journal), vol. 18, no. 2, pp. 161-169, 2011.

[17] V. . Praag, V.L., Stevens, A.J.P., Houtte, "How Humor Makes or Breaks StudentTeacher Relationship: A Classroom Ethnography In Belgium," in Teaching and Teacher Education, 2017, pp. 393-401.

[18] A. Ogunsiji, Y., Farinde, "Language, Gender, and Culture," Br. J. Art Soc. Sci., vol. 6, no. 2, pp. 202-210, 2012.

[19] R. Lakoff, Language and Woman's Place. New York: Harper \& Row Publisher, 2001.

[20] B. . Pallawa, "Function WorMt of Andio Language Viewed from Syntactical Aspect," Acad. J. Interdiciplinary Stud., vol. 2, no. 2, pp. 175-185, 2013.

[21] G. Hiver, P., Whitehead, Sites of Struggle: Classroom Practice and the Complex Dynamic Entanglement of Language Teacher Identity. Elsivier, 2018.

[22] M. Göçtü, R. and Kir, "Gender Studies in English, Turkish, and Georgian Languages in Terms of Grammatical, Semantic and Pragmatic Levels," in Procedia-Social and Behavioral Sciences 158, 2014, pp. 282-287.

[23] E. Filippova, "Developing appreciation of Irony in Canadian and Czech Discourse," J. Pragmat., vol. 74, pp. 209-223, 2014.

[24] J. . Mey, Pragmatic an Introduction. USA: Blackwell Publishing, 2001.

[25] M. Liantada, C., Bringing Into Focus Multilingual Realities: Faculty Perceptions of Academic Language on Campus. Lingua Elsivier, 2018. 